\title{
Proceedings, Conclusion and Consequences from the Norwegian Expert Group on Transgender Health and Legal Rights
}

Esben Esther Pirelli Benestad*

University of Agder, Norway

\begin{abstract}
Issued by the Ministry of Health and care, the directorate of health organized an expert group that through all 2014 and some months into 2015 worked on issues of legal right to gender and on the health services to individuals within the gender incongruent group in Norway. The background was expressed dissatisfaction with the state of affairs expressed both from organizations for gender incongruent, from the legal and health professions and form human rights organizations. The report delivered from the expert group in April 2015 confirms the needs for improvement on many levels both in the legal and in the health systems of Norway. The expert group's conclusions are in very short: Self-determined gender and health-care organized by the principle of lowest effective level of care and the smallest effective dose of treatment on all levels. The right to self-determined gender down to the age of six with caretakers' approval was issued July first 2016. The health part of the report is as of yet not implemented.
\end{abstract}

\section{Background}

Health-care in Norway is to a large extent financed/endorsed by the State in a socialized system. Clients in primary care services pay part of a general practitioner's (GP's) salary, but most is endorsed by the State. Hospital care is practically for free on all levels concerning medically necessary treatment; all is endorsed by the State. This also includes hormonal and/or surgical gender affirming treatment. Some diagnoses in this system that cannot be treated by the GP alone must be referred to officially chosen hospital(s). The understanding is that complex, difficult diagnoses concerning small groups of clients should be referred to one or perhaps two hospitals in order to obtain the best possible offer of treatment. Hospital chosen for such special tasks have what in Norway is named a "National function" on that very diagnose and treatment [1]. Other institutions will not be endorsed if offering health care to these selected groups of clients. Other health workers on lower levels of the system risk sanctions from the health authorities it they offer treat to clients in these selected categories.

For the last sixteen years, health-care for individuals seeking to be diagnosed as transsexual F64.0, have been met with such a National Function. Hence diagnose and treatment has been monopolized by one department at Oslo University Hospital, a State owned institution. The exact ward is presently named the NBTS (National treatment service for transsexuals).

Like other selected groups of clients, those who were/are not diagnosed with F64-0, and/or do/did not want to be evaluated by the NBTS team, had and still have no formalized offer in the Norwegian health-care system. Neither do they have any option of second opinion, since there is but one hospital offering state endorsed care [1].

As for the access to change of legal gender, this used to require removal of gonads, and that removal had to be performed within the National function at Oslo University Hospital. In a short period before July 2016, certificates from procedures performed by other institutions abroad were accepted as proof of eligibility for legal change of gender.

As the number of treatment seeking transgender individuals rose, and the NBTS refused treatment to many, and many others were unhappy with the treatment they received, many came to order hormones over the internet and hence self- medicated without any monitoring. Many have also gone abroad for gender confirming surgery. The fact that many transgendered individuals did not receive proper treatment was pointed out and complained about both by interest organizations like the organization LLH for lesbian, gay, bisexuals and transpeople and also by Amnesty International and the European Commissioner for Human Rights [1].

The Norwegian Ministry of Health and Care cooperates with the Norwegian Directorate of Health in questions concerning health administration and health professionality. In 2013 the Norwegian Minister of Health and Care Services missioned the Directorate of Health to establish an expert group that should evaluate present state of health-care and legal rights for the trans ${ }^{\star}$ gendered (including all those that in the following report came to be called "gender incongruent") in Norway. In addition to the already mentioned state of affairs came insights rendered by scientific research, confirming that which was pointed out both from national and international sources [2-4]. Time was ripe for an expert group to look into the different aspects and perspectives involved.

In short the mandate of the expert group became as follows:

The group should study the present conditions for change of legal gender status in Norway, and evaluate needs for - and suggest changes to the present health-care offers to individuals who experience gender dysphoria [1].

The group came to consist of 16 individuals plus three secretaries. The experts were recruited from the health-, research- and legal fields and from interest groups. One member, the group's endocrinologist, was hired in from Sweden, where he had been member of an equivalent expert group. In addition, on the health professional side,

${ }^{*}$ Corresponding author: Esben Esther Pirelli Benestad, Phycician, family therapis IAP, Specialist in clinical sexology NACS, Professor of sexology, University of Agder, Norway; Tel: 0047 97533543; E-mail: esben.esther@uia.no

Received December 22, 2016; Accepted February 04, 2017; Published February 11,2017

Citation: Benestad EEP (2017) Proceedings, Conclusion and Consequences from the Norwegian Expert Group on Transgender Health and Legal Rights. J AIDS Clin Res 8: 663. doi: 10.4172/2155-6113.1000663

Copyright: (C) 2017 Benestad EEP. This is an open-access article distributed unde the terms of the Creative Commons Attribution License, which permits unrestricted use, distribution, and reproduction in any medium, provided the original author and source are credited. 
were two psychiatrists, one of whom the present leader of the NBTS; two psychologists and one specialist in general medicine, all rich in experiences with gender incongruent clients; one specialist in community medicine; one professor of gynecology and obstetrics; one professor of sexology (the author of this paper) and one specialist in sexological counselling. There was one representative from the researcher side and four from four different interest organizations. The legal side was represented by three lawyers, one of whom were the leader of the group (Paulsrud), one other has published on sexual rights. The four interest organizations, represented with one person each, were from the Harry Benjamin Resource Center (HBRS), the federation for trans-people (FTP), the "Queer Youth", the largest LGBT organization of Norway called the association for gender and sexuality diversity, now carrying the acronym FRI. Five of the delegates have themselves personal experiences within the realm of gender incongruence.

The group met regularly all through 2014 and some month into 2015. In the process other groups like "Queer world" and other researchers on legal and health-care issues concerning gender incongruence were invited in to present their views and insights. The state of gender incongruence in many other states outside Norway was referred in written form to the group. The learning curve of several of the expert group participants became very steep.

\section{The Administration of the Proceedings}

It is certainly a challenge to administrate a group of this size and diversity on to a point where hopefully a well formulated paper that could represent reasonably general agreement within the group, could be presented to the principal: The Norwegian Ministry of Health.

During the time of the proceeding, the group first spent a weekend together sharing both professional and leisure time. Each meeting was thereafter of one work-day's duration, each time focusing of one or more aspect of the mission. Some members (amongst them the author of this paper) were asked to give more detailed views of their insights and ideas as to how the different challenges both in health and legal, care and rights could be solved. Each and every one were also given time to describe their experiences with the health care offers at Oslo University Hospital, the NBTS ward, and their needs and wishes for the future. These exchanges as viewed from this author's perspective were delivered in a frank, but friendly way to the effect of not creating emotions that could harm the making of a useful final document.

One technique widely used by the group leader throughout the proceedings, was to assemble 4-5 members in 3-4 groups to discuss the day's issues, and deliver this both orally and written to the plenary. Thereafter, followed a discussion that aimed to take in differences of opinion, obscurities, and to point out issues forgotten or insufficiently worked with. All material presented was taken down, edited by the secretaries, sent out to all members for considerations, comments and alterations before the next meeting. There were altogether 8 meetings. From January 2014 to August the same year, the efforts over this first perio aimed at building a common body of knowledge within the group. This should include research findings, experience based knowledge, knowledge of users and the scrutiny of users all through the process. The group slowly added together the puzzle that eventually became the final report.

\section{Issues Debated through the Proceedings}

As the final report points out, there is scarce knowledge based insights to the issues involved and at stake. There were no Norwegian guidelines as to how to work with individuals who experience gender dysphoria.
International guidelines and especially the World Professional Association for Transgender Health's (WPATH's) Standards of Care (SOC) were thoroughly read and evaluated for Norwegian contexts.

The expert group realized that the extent and content of today's health-care offers have been both fragmentarily and insufficiently described. However, through literature search and by means of both the clinical and the personal insights within the group, the body of knowledge grew and the group felt competent for decisions.

The issues the expert-group was missioned to debate were:

- What are the ongoing practice and guidelines for therapy and follow up in the health-field concerning gender incongruent individuals?

- What are the present health-care offers, and how do they work?

- What is the present practice concerning change of legal gender and how thus the rules operate in practice.

- Evaluation of the demand for castration as a condition for legal gender change and the possible consequences if that demand is removed?

- What should be the criteria for legal gender change?

- Evaluate the need for and suggest changes in the present healthcare offers and possibly other actions in order to ensure and secure comprehensive and beneficial patient processes on all levels of the Norwegian Health Care System.

It goes beyond the scope of this paper to describe all the details and considerations of the whole report, but some very basic recommendations will be described later in this paper.

\section{Some of What Caused Extra Debate in the Proceedings}

Words and concepts were a major issue. Are there words and concepts that can unite the different fractions within the diverse field of gender incongruence? The term trans did not fill the needs of some in the group. It came out that exactly this term: Gender incongruence, was acceptable both for the professionals, the interest groups, the legal representatives, the researchers and the individual members of the group. In many ways this represented a turning point and a better basis for agreements. It was a long longed for concept for all to agree upon. The agreement was reinforced by the intentions of the ICD11, were that very term probably will come in to general use $[5,6]$.

Prevalence was another issue. Is the use of Oslo University Hospital as a National Function in accordance with the prevalence of gender incongruence? The secretariat struggled long to get records from the NBTS. Those records operated with much smaller numbers that what have been found in recent international statistics, where the prevalence of self-declared transgender is around 1\% [7]. This prevalence greatly exceeds the basis for the present centralization and monopolization.

The health-care offers to children before puberty was also an issue of debate that in many aspects was quite congruent with the ongoing debate in the proceeding leading up to the ICD 11, where there is presently a fifty-fifty stand between those who want and those who don't want the use of a future diagnose called gender incongruence in childhood $[5,8,9]$.

Concerning the access to legal gender there was a debate as to whether or not Norway should demand a time of reflection as the Danes had done in their decision of 2014 [1]. 
In the wake of the hearings (the report was sent to many professional and interest individuals, groups and organizations after it was delivered to the Ministry of Health), there was a silent debate on one of the main principles in the main and unanimous recommendations of the expert group, namely the principle of lowest effective level of care, which shall be returned to.

The following will give some insights to the final recommendations by the expert group. It is divided into a part concerning the legal, right to right gender part, and a part concerning health-care named health to all genders.

\section{Right to Right Gender}

The unanimous recommendation of the expert group was selfdetermined legal gender. The bottom age limits were not determined in detail. Parents' or peers' consent should be required for individuals under the age of sixteen. There should be no demand for any professional evaluation or recommendation, no demand for any bodily adjustments, just one personal declaration of gender.

There was a dissent on the issue reflection time, meaning: You apply for change of legal gender, but you have to apply again after a number of weeks. There were two different opinions as to what exact amount of time required amongst the minority (altogether 3 of 16) who wanted such compulsory time for reflection. That kind of procedure had been introduced in one of Norway's neighbor countries, namely Denmark $[1,10]$.

It was not within the mandate of the expert group to give any concrete recommendations on the issue of a third (gender) option, but nevertheless the group recommended the state officials to rule out conditions and consequences concerning this issue [1].

\section{Health to all Genders}

In the report the expert group states (in this authors translation):

- The review of the existing offers of health services demonstrates that many do receive the health care the wish for. At the same time, it has become clear for the expert group that there are numerous lacks and challenges in the services offered today. This leads to a state were many who have the right to health care in relation to gender dysphoria, do not get the help they need and wish for.

- There is by the evaluation of the expert group, a great need for increased competence on all levels of the health services to ensure that human beings who experience gender dysphoria receive offers of professionally proper health-care and are met by health personnel with understanding and respect.

- The expert group is of the opinion that actions must be taken to build the necessary competence for diagnostic evaluation and treatment of patients with gender dysphoria on all levels of the health care systems.

- The experts group recommends to offer heath care to more groups who experience gender dysphoria than the case is today, and the aim that this health-care can be given at the right level, demands guidelines and routines for necessary diagnostics and treatment in the regions [1].

The group agreed on two principles by which to accomplish the changes needed. One principle is clearly expressed in the final report, the other not expressed as this author does it, but nevertheless clearly present in the report.
Principle number one is in Norwegian called the LEON principle, an acronym to describe the lowest effective level of care (LELC in English?).

Hormone therapy is well within what GPs do in their daily practice. They regularly prescribe and monitor hormonal replacement therapy for post-menopausal females, plus other individuals who have lost their gonadal hormone production, and they prescribe and monitor hormonal anti-conception pills. Hence the administration of gender confirming hormonal treatment is not outside their capacity. The GP is also well accustomed to refer to local or more central institutions or to specialist practicing within or outside the Norwegian Health-care system. Hence the GP can refer clients to endocrinologists in cases of doubt or complexity, to surgery when minor procedures are wanted, or for that matter to gender incongruence support institution, to sexual aids, to gender confirming aids and to genital gender affirming surgery.

All but the need for genital reconstructive surgery can be met on lower levels of the health care system than at the Oslo University Hospital. There is no need to use the most expensive ward in the country to perform procedures like breast removal, breast implants, liposuction, hair removal etc. since the competence needed for those procedures is widespread.

There is, however, a need for a flexible and reachable team that can give guidance as to who should and who should not receive such hormonal and/or surgical treatment. Although the actual organization of such a team is not clearly described in the document, the expert group left it to the health bureaucrats to organize this service and recommended the sexology profession for the task [1].

Oslo University Hospital is by the expert group thought to care for the most difficult and complex challenges in the gender incongruence population and for the gender confirming genital surgery.

Principle number two is that which this author in Norwegian names the MED principle, an acronym to describe the lowest effective dose (LED in English?). In Norway, you still have to change your genitals in order to receive Stately endorsement for a wig. Even when a wig is actually all your need in your gender affirming endeavors. The point stressed in the expert report, is that no one should be forced to receive more treatment, more hormonal and/or surgical interventions than they subjectively need, and still receive state support.

\section{Consequences of the Report Thus Far}

The report was delivered to the Norwegian Minister of Health the $10^{\text {th }}$ of April 2015 [1]. The Title of the report in this author's translation is "Right to right gender, health to all genders."

The first of July 2016 the Norwegian government instituted the new law of self-determined legal gender down to the age of six. Those under the age of sixteen must have an age adequate consent from parents and/or other caretakers. By the end of January 2017 about five hundred had applied. No one will be refused. In comparison, in the period from January first 2011 to December thirty first 2014 the NBTS had offered hormonal treatment to eighty female to male (FtM) and to fifteen male to female (MtF), who by them were diagnosed with F64.0, transsexualism. In the same period NBTS performed gender affirming genital surgery on forty FtM and $22 \mathrm{MtF}$.

The Norwegian Department of Health and the large health administrating bureaucracies of Norway is still working with the full, part of or no implementation of the expert-group's recommendations on the level of health care offers to the gender incongruent population of Norway. 
Citation: Benestad EEP (2017) Proceedings, Conclusion and Consequences from the Norwegian Expert Group on Transgender Health and Legal Rights. J AIDS Clin Res 8: 663. doi: 10.4172/2155-6113.1000663

Page 4 of 4

It is known that two minorities, the NBTS and HBRS, within the expert group have lobbied against the LELC principle. The HBRS suggests on their webpage rather one more institution within the national function.

The hearings were on the general positive to the report. The GP's union were in favor of a continued centralized health-care system for those who experience themselves as gender incongruent.

The Ministry of Health is when this paper is written, still working with how and when and to what degree the report will be implemented. Why this takes so long is still to be found out, if it ever becomes transparent.

\section{Some Reflections and Concluding Remarks}

It is also yet to be found out if GPs will accept individuals with gender incongruence as part of their primary responsibility. A line for advice and referral as suggested in the report is definitely a condition.

The organization FRI in cooperation with the University of Agder, Norway arranged a course in gender incongruence health-care for GPs in December 2016. The course was recommended by the doctor union of Norway. The number of attendees could definitely have been higher, but those who were there reported positively.

Likewise it is yet to be seen whether or not the more orthodox and binary oriented group within the gender incongruent population will let go their "privileges" in have a National Function all by themselves, even though their wishes and need should be well taken care of in a more decentralized system. The same goes for the psychiatrists now ruling the field of gender incongruence from their central and hence quite powerful position.

\section{References}

1. Paulsrud K, Arver S, Haraldsen I, Aarre T, Aanerød LMT, et al. (2015) Rett til rett kjønn - helse til alle kjønn, Utredning av vilkår for endring av juridisk kjønn og organisering av helsetjenester for personer som opplever kjønnsinkongruens og kjønnsdysfori. Helsedirektoratet, Oslo, Norway 40.

2. Ros J (2013) Alskens folk. Levekår, livssitusjon og livskvalitet for personer med kjønnsidentitetstematikk. Likestillingssenteret, Hamar.

3. The Commisioner for human rights (2009) Human rights and gender identity Issue paper. The Commisioner for human rights, Council of Europe, Strasbourg.

4. TGEU (2014) Checklist legal gender recognition.

5. Drescher J, Cohen-Kettenis P, Winter S (2012) Minding the body: Situating gender identity diagnoses in the ICD-11. Int Rev Psychiatry 24: 568-577.

6. Cuypere GD, Knudson G, Bockting W (2010) Response of the World Professional Association for transgender health to the proposed DSM 5 criteria for gender incongruence. Int J Transgend 12.

7. Clark TC, Lucassen MFG, Bullen P, Denny SJ, Fleming TM, et al. (2014) The health and well-being of transgender high school students: Results from the New Zealand adolescent health survey (Youth'12). J Adolesc Health 55: 93-99.

8. Benestad EEP (2009) Addressing the disturbed, like ripples in water Intervention with the social networks of children who transe. Sex Relation Ther 24: 9 .

9. Ehrensaft D (2012) Gender identity disorder to gender identity creativity: True gender self child therapy. J Homosex 59: 337-356.

10. Regjeringen no (2016) Prop 74 